\title{
Effects of stock differences in the acceleration of puberty in female mice
}

\author{
J. J. Cowley, R. Pewtress and S. McDonald \\ Hatfield Polytechnic, School of Natural Sciences, College Lane, Hatfield, Herts AL10 9AB, U.K.
}

\begin{abstract}
Summary. Newly born TO strain female mice were exposed daily to the urine from male albino mice of the same and CFLP strains, from feral mice carrying Robertsonian translocation chromosomes and to water as a control condition. At 21 days of age, when exposure was discontinued, there were differences in body weight between treatments which were not present when adult. Exposure to urine from mice with Robertsonian translocations did not accelerate puberty and the interval between vaginal opening and first oestrus was longer ( $4 \cdot 2$ days) than in mice exposed to the urine from the albino strains ( 1.8 days). Mice exposed to the urine from the Robertsonian stock were in dioestrus more often than those exposed to the urine from laboratory strains. The Robertsonian mice also differed in their behaviour in an open arena in that they passed fewer faecal pellets than those exposed to the urine from the albino mice. The water control mice defecated the least frequently. The mice exposed to the Robertsonian urine were less active than the laboratory strains but the differences did not reach an acceptable level $(P<0.06)$ of significance.
\end{abstract}

Keywords: pheromones; mice; translocation chromosomes; sexual development

\section{Introduction}

Mice derived from circumscribed feral populations have been extensively used in the study of mammalian aneuploidy. The feral mice can carry spontaneously occurring fusion chromosomes (translocation chromosomes) that can be transferred, through pairing, with laboratory strains. The identification and isolation of mice with particular translocation chromosomes has facilitated the investigation of a range of human conditions, with chromosomal imbalance, including trisomy 21 (Down's syndrome). The Robertsonian mice used in the present study when bred produce offspring which, if mated with normal laboratory mice, produce trisomy conceptuses (Epstein, 1985, 1986; also see Searle, 1985, for review of chromosomal variants). There is a strong degree of homology between human chromosome 21 and chromosome 16 in the mouse and this is expressed at both the biochemical and morphological level (Oster-Granite et al., 1986).

In a laboratory strain of mouse (TO) the urine from mothers designated as inactive, on the basis of their movements in an open arena, affected target mice by reducing activity levels while urine from similarly categorized active mice enhanced the recipients' activity (Cowley \& Smale, 1986). Morphological differences between donors were also associated with changes in the recipients. The daily exposure of newly born female mice to the urine of lactating mice with a small ano-genital distance accelerated the onset of first oestrus while the urine from donors with a large ano-genital distance was without effect (Cowley \& Pewtress, 1986). The question posed here is whether exposure during infancy to the urine of donors of different laboratory strains and others with particular Robertsonian chromosomal characteristics is able to modify the rate of sexual development and the subsequent activity of the mice. The exposure of female mice to soiled bedding or the urine of adult males of the same strain and to male descendants of wild mice is known to enhance puberty 
(Vandenbergh, 1967, 1969; Cowley \& Wise, 1972; Drickamer, 1974; Massey \& Vandenbergh, 1981) but there is little information about the relevant effectiveness of strain differences although Drickamer (1983) has shown that degree of relatedness (kinship) within a strain does not differentially affect the acceleration of female puberty.

Strain differences in the action of pheromones on other aspects of reproduction have also been reported. The blocking of pregnancy in mice was observed by Bruce (1961) to be more effective if the unfamiliar male was of a strain different from that of the stud male. Whereas exposure to same strain males blocked pregnancy in about $25 \%$ of females the proportion was of the order of $70-80 \%$, in some tests as high as $100 \%$, when a male of a different strain was introduced (Parkes \& Bruce, 1961). The greater effectiveness of the unfamiliar strain in inducing the block to pregnancy has encouraged us to examine whether exposure of newly born females to the urine of different strains of male mice would differentially affect the retardation or acceleration of the onset of first oestrus.

\section{Materials and Methods}

Animals. Urine was collected from four groups of mice of which two were laboratory albino strains (CFLP and TO) and two were strains with Robertsonian autosome translocations Rb9(9,16)Rma and Rb(11,16)2H. The CFLP and the Robertsonian stock were obtained from the Medical Research Council Neurobiology Unit, some 3 months before the start of the experiment. TO strain mice were bred in our laboratory.

Urine collection and application. The urine was collected from the mice at 2-3-day intervals. The mice were held over a Petri dish and the flanks of the animal gently squeezed to promote voiding the urine. Care was taken to ensure that there was no contamination of the urine from one strain with that of another. The glassware was used only once across strains and, similarly, in applying the urine to the recipients the paintbrushes and containers were kept separate for each treatment (see Cowley \& Wise, 1972; Cowley \& Smale, 1986, for further details of the procedure). The urine was diluted by mixing 1 part of urine in 5 parts of distilled water. When not in use urine was maintained at $-17^{\circ} \mathrm{C}$ and when required thawed gently at room temperature. The urine was applied from Day 1 to 21 days of age to the dorsal surface of the nose of the recipients using 4 or 5 gentle strokes with a soft watercolour paintbrush.

All recipients were newly born TO mice. Mice born on the same day were mixed together and 5 or 6 female infants were randomly distributed to each mother. The infants were weighed before starting treatment, when the mothers were removed at 21 days, at vaginal opening and again at 85 days of age. Infants in any one treatment condition (Groups 1-4, see Table 1) were exposed once daily to urine from the same donors (or water in Group 5). After vaginal opening vaginal smears were taken daily for 10 consecutive days and thereafter the mice were left in their original litters undisturbed. Food and water were available at all times and the cages were cleaned twice weekly.

Open arena activity. The activity of the mice was recorded in an arena on 4 successive days when they were between 63 and 73 days of age. The arena was mounted on an automated activity recorder (Panlab Acti System, Ormed Ltd, Welwyn Garden City, U.K.) which allows for the simultaneous recording, at different levels of sensitivity, of different components of the movements of the mice in the arena. We have found it useful to test the animals for 2 min each day at levels designated as ' 4 ' and ' 7 '. The former is triggered by movements such as rapidly lowering the body onto the surface from an upright position and hard running or jumping movements about the arena. The setting at the lower level of sensitivity (' 7 ') records the meanderings about the arena and it is this type of activity that is often recorded in an open field test. The number of faecal pellets passed during the test trials was also recorded.

Statistical analysis. One-way analysis of variance and Duncan's New Multiple Range Test were carried out with the use of SPSS (2nd edition) and a DEC 1091 Computer unless otherwise stated.

\section{Results}

\section{Body weight}

The mean differences in body weight between treatments were not significant at birth and at 14 days of age. At weaning there was, however, evidence of a marked difference in mean body weight between treatment groups $(P<0.003)$. The mice (mean \pm s.e.m.) in Group $4(11.55 \pm 0.20 \mathrm{~g})$ and Group $5(11.32 \pm 0.47 \mathrm{~g})$ were the lightest and the mice in Group 5 also weighed less than those in Group $1(13.14 \pm 0.47 \mathrm{~g}), 2(12.66 \pm 0.30 \mathrm{~g})$ and $3(13.22 \pm 0.47 \mathrm{~g})$. The differences between the means were significant at $P<0.05$ in all instances. The mice in Group 4 were also lighter than 
Table 1. Effect of exposing infant mice to urine from adult males during the suckling period on the age of vaginal introitus and onset of first oestrus

\begin{tabular}{|c|c|c|c|c|c|}
\hline Group & $\begin{array}{c}\text { Donors of } \\
\text { urine }\end{array}$ & $\begin{array}{l}\text { No. of } \\
\text { mice }\end{array}$ & $\begin{array}{c}\text { Age at } \\
\text { vaginal opening } \\
\text { (days) }\end{array}$ & & $\begin{array}{l}\text { Age at } \\
\text { first oestrus } \\
\text { (days) }\end{array}$ \\
\hline 1 & TO & 10 & $25 \cdot 10(0 \cdot 54)$ & & $27.70(0.47)$ \\
\hline 2 & CFLP & 12 & $27.00(0.52)$ & & \begin{tabular}{l|l}
$\mid$ & $28.08(0.42)$
\end{tabular} \\
\hline 3 & $\mathrm{Rb} 9(9,16) \mathrm{Rma}$ & 12 & $26.33(0.96)$ & $\begin{array}{ll}1 & 1 \\
1 & 1\end{array}$ & \begin{tabular}{ll|l} 
& $29.92(0.57)$
\end{tabular} \\
\hline 4 & $\mathrm{Rb}(11,16) 2 \mathrm{H}$ & 8 & $25.50(1.48)$ & 1 & $30.63(1.19)$ \\
\hline 5 & (Water) & 12 & $27 \cdot 00(0 \cdot 75)$ & 1 & $30.75(0.52)$ \\
\hline
\end{tabular}

Values are mean (s.e.m.)

No significant difference $(P<0.05)$ between means connected by the solid lines.

Means connected by the broken lines are not significantly different, $P<0.02$

(Duncan).

those in Groups 1 and $3(P<0.05$ in both instances $)$ but there were no other significant differences and no evidence that the differences in body weight persisted into adult life.

\section{Vaginal opening and first oestrus}

There were no statistically significant differences between the groups in the mean age of vaginal opening, but the mean age of onset of first oestrus did differ according to treatment $(P<0.003)$. The mice in Groups 1 and 2 showed accelerated onset of oestrus when compared with Groups 3, 4 and 5. Neither Groups I and 2 differed in the age of onset of first oestrus and nor did Groups 3 and 4. Table 1 summarizes the findings and shows the differences between the treatment groups using the Duncan's test at both the 0.05 and 0.02 level of significance. Early exposure to the urine of male mice may or may not have an accelerating effect on the onset of puberty in female TO recipients.

There were marked differences between the treatment groups in the time between vaginal opening and onset of first oestrus $(P<0.006)$. The mice in Groups 2 and 4 occupy the extreme positions with a mean delay of 1 day in the former and 5 days delay in the latter. Mice which on 2 or more occasions were in oestrus were compared with the number of mice in the same treatment group that failed to come into oestrus or did so only once. A $\chi^{2}$ analysis showed marked differences between treatments $\left(\chi^{2}=15 \cdot 4\right.$; d.f. $=4 ; P<0.01)$. Mice in Groups 3, 4 and 5 showed little evidence of cyclicity $(0 \%, 25 \%$ and $16 \%$ respectively) whereas in Groups 1 and $259 \%$ of mice showed cyclicity during the 10-day period.

Over the 10 days there were differences between treatments in the number of days when the mice were in dioestrus $(P<0.001)$ and metoestrus $(P<0.01)$. The mice in Groups 3 and 4 were in dioestrus more often than those in other groups $(P<0.05)$. The mice in Group 4 had fewer metoestrous smears than did those in Group $5(P<0.05)$. There were no other significant differences in cell content between the treatment groups.

The mean differences in overall activity on measures ' 4 ' and ' 7 ' did not differ significantly between treatment groups. There was some indication, however, that the mice in Groups 3 and 4 scored lower for both levels of activity, on successive days, than did mice in Groups 1, 2 and 5. When the mean scores for both sensitivity levels were plotted over days the mice in Groups 3 and 4 tended to be the least active, mice in Groups 1 and 2 the most active and those in Group 5 occupied an intermediate position (Fig. 1). It was only for level ' 4 ' activity, however, that these differences approached an acceptable level of significance $(P<0 \cdot 06)$.

There were no marked differences between treatment groups in the total number of faecal pellets deposited over the 4 days of testing $(P<0.06)$ although the mice in Group 5 deposited fewer stools than did those in Group $2(P<0.05)$. The pattern of results is, however, more complex. A two-way analysis of variance in which mice in Groups $3+4$ were compared with those in Groups $1+2+5$ showed that there was a significant difference in the number of faecal pellets $(P<0.01)$ 


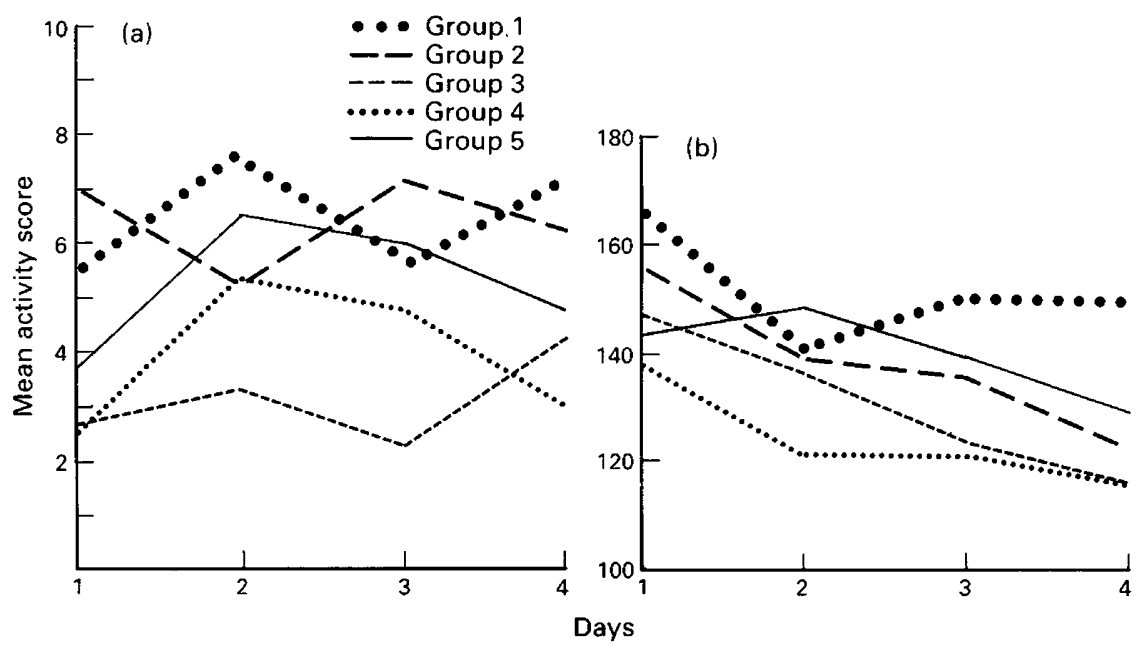

Fig. 1. Levels of activity (a, at ' 4 '; b, at ' 7 ') of the mice in Groups 1-5 as a function of days tested.

and with a marked interaction between mean number of faecal pellets and days tested $(P<0 \cdot 005)$. The pattern of defecation over days was different as a function of treatment during infancy, with the mice in Groups 3, 4 and 5 depositing fewer faecal pellets than those in Groups 1 and 2.

\section{Discussion}

The results show that at the end of 21 days of exposure to the urine from male mice of different stock there are marked differences in body weight between treatment groups. Mice exposed to the urine of one of the Robertsonian stock (Group 4) and those exposed to the water control treatment (Group 5) showed an absence of any accelerated growth while mice exposed to the urine of the other Robertsonian stock (Group 3) and the laboratory strains (Groups 1 and 2) were heavier. The accelerating effect of exposure to male urine on the body weight of female mice of the same strain has been recorded elsewhere (Cowley \& Wise, 1972) and a similar increase in weight was observed when female infants were reared, during the first 21 days of life, in proximity to adult males (Fullerton \& Cowley, 1971). The results suggest that the growth acceleration is dependent on the donor stock and that where changes in weight gain occur they are transitory.

The mice that are the lightest at weaning are also those in which there is no accelerated onset of puberty. The picture is, however, more complex as mice exposed to the urine of the Robertsonian Group 3 males were heavier, at this age, than any of the other groups, but they are also like the Robertsonian Group 4 and water control in that they show no early onset of puberty. Drickamer (1974) has suggested, on the basis of his own extensive and other studies, that in the house mouse there is no critical body weight that is associated with attainment of first oestrus. The apparently contradictory findings may be due to the very different ages at which the mice in his studies and our own have been exposed to the secretions-post-weaning as opposed to pre-weaning exposure in our experiments. In the mouse the brain is growing fastest during the neonatal period and it is a period during which the olfactory brain is susceptible to change through the action of volatile substances including those found in the urine (Harvey \& Cowley, 1984). It is also a period, at least in the rat, when the mechanisms underlying the control of puberty are being further established and integrated (see Ojeda et al., 1986, for detailed discussion and reference to other literature).

We have suggested that in the mouse the composition of the urine reflects the neuroendocrine state of the donor and provides, through the action of pheromones, a means of modifying and 
hence controlling the sexual development and behaviour of recipients (Cowley \& Pewtress, 1986). However, the urine from the feral derived populations, and with the chromosome anomalies that we have described, failed to modify the rate of sexual development when the infant recipients were from a laboratory strain. This is not just a strain difference effect, as the CFLP (Group 2) were able to do so and may have been a little more effective than the TO (Group 1) mice that were of the same strain as the recipients. The question arises as to whether laboratory strains acquired the accelerating properties through selection (domestication) or whether the failure to do so in the Robertsonian mice reflects the particular chromosomal anomalies of these feral derived stock. The Robertsonian mice (Group 4) are reported by Searle (1985) as having risen spontaneously in the laboratory from stock derived from the tobacco mouse (Mus musculus poschiavinus) which has 7 pairs of fusion chromosomes and is found in high-altitude valleys in south-east Switzerland. The results show that the urine of this stock is as ineffective as that of the Robertsonian (Group 3) and water control mice in modifying the rate of sexual development, suggesting that the derivation of the mice has not further increased the ineffectiveness of the urine in accelerating the early onset of puberty. The TO recipients remain sensitive to the secretions of their own and other allied strains but a matchmismatch condition pertains with the urine from the Robertsonian mice, unable, presumably, to act on the olfactory centres.

The results show that the urine of the Robertsonian mice did not accelerate sexual development, and associated with this there was a failure to initiate regular oestrous cycles and the chromosomal anomalies presumably contribute to the failure. Laboratory mice can be selected, over successive generations, for early and late onset of first oestrus. The lines selected fail to respond after 6 generations to an acceleration or delay of first oestrus when exposed to the urine of male and female conspecifics. The results show that the selection produced a base line at which the urine could no longer exercise further change (Drickamer, 1981). Chromosome 17 in the mouse carries the MHC (Major Histocompatibility Complex) group of genes and the genes may themselves be responsible for providing each individual with a characteristic odour. The Bruce effect is more readily elicited when the MHC gene complex of an unfamiliar male differs from that of the stud male (Yamazaki et al., 1983, 1986). Further, the block to pregnancy could be demonstrated when the unfamiliar and stud male differed only in terms of a mutation of $\mathrm{H}-2 \mathrm{~K}$ from the $\mathrm{MHC}$ region. Whether Chromosome 16, which is the chromosome implicated in the mouse model of Down's Syndrome (Epstein et al., 1985), is involved with the acceleration of puberty remains a matter for further enquiry. In persons with Down's Syndrome, however, sexual functions are grossly impaired and there is little unanimity as to the age of onset of puberty (see Smith \& Berg, 1976, for review).

The MRC Neurobiology Unit provided the Robertsonian and CFLP strain mice and we are indebted to Dr R. Balázs and Dr B. W. L. Brooksbank for arranging their transfer. We thank Ms L. Doyle for assistance in the preparation of the manuscript.

\section{References}

Bruce, H.M. (1961) An olfactory block to pregnancy in mice. Part 1: Characteristics of the block. Proc. $4 \mathrm{th}$ Int. Congr. Animal Reprod., The Hague 159-162.

Cowley, J.J. \& Pewtress, R.K. (1986) Post-parturition and late lactation urine: long-term effects of exposure on mouse activity and sniffing behaviour. Reprod. Nutr. Develop. 26, 113-126.

Cowley, J.J. \& Smale, S. (1986) Long-term effects on activity in female mice following exposure to urine from lactating mothers. Physiol. Behav. 36, 115-121.

Cowley, J.J. \& Wise, D.R. (1972) Some effects of mouse urine on neonatal growth and reproduction. Anim. Behav. 20, 499-506.
Drickamer, L.C. (1974) Sexual maturation of female house mice: social inhibition. Devl Psychobiol. 7, 257-265.

Drickamer, L.C. (1981) Acceleration and delay of sexual maturation in female house mice previously selected for early and late first vaginal oestrus. J. Reprod. Fert. 63, 325-329.

Drickamer, L.C. (1983) Male acceleration of puberty in female mice (Mus musculus). J. comp. Psychol. 97, 191-200.

Epstein, C.J. (1985) Mouse monosomies and trisomies as experimental systems for studying mammalian aneuploidy. Trends in Genetics, 1, 129-134. 
Epstein, C.J. (1986) The Consequences of Chromosome Imbalance. Cambridge University Press, Cambridge.

Epstein, C.J., Cox, D. \& Epstein, L.B. (1985) Mouse trisomy 16: an animal model of human trisomy 21 (Down syndrome). Ann. N. Y. Acad. Sci. 450, 157-168.

Fullerton, C. \& Cowley, J.J. (1971) The differential effect of the presence of adult male and female mice on the growth and development of the young. J. Genet. Psychol. 119, 89-98.

Harvey, F.E. \& Cowley, J.J. (1984) Effects of external chemical environment on the developing olfactory bulbs of the Mouse (Mus musculus). Brain Res. Bull. 13, 541-547.

Massey, A. \& Vandenbergh, J.G. (1981) Puberty acceleration by a urinary cue from male mice in feral populations. Biol. Reprod. 24, 523-527.

Ojeda, S.R., Urbanski, H.F. \& Ahmed, C.E. (1986) The onset of female puberty: Studies in the rat. Recent Prog. Horm. Res. 42, $385-440$.

Oster-Granite, M.L., Gearhart, J.D. \& Reeves, R.H. (1986) Neurobiological consequences of trisomy 16 in mice. In The Neurobiology of Down Syndrome, pp. 137-151. Ed. C. J. Epstein. Raven Press, New York.
Parkes, A.S. \& Bruce, H.M. (1961) Olfactory stimuli in mammalian reproduction. Science, N.Y. 134, 1049.

Searle, A.G. (1985) Chromosomal variants. In Issues and Reviews in Teratology, pp. 324-357. Ed. H. Kalter. Plenum Press, New York.

Smith, G.F. \& Berg, J.M. (1976) Down's Anomaly, pp. 40-41. Churchill Livingstone, Edinburgh.

Vandenbergh, J.G. (1967) Effect of the presence of a male on the sexual maturation of female mice. Endocrinology 81, 345-349.

Vandenbergh, J.G. (1969) Male odor accelerates female maturation in mice. Endocrinology 84, 658-660.

Yamazaki, K., Beauchamp, S.K., Wysocki, C.J., Bard, J., Thomas, L. \& Boyse, E.A. (1983) Recognition of H2 types in relation to the blocking of pregnancy in mice. Science, N.Y. 221, 186-188.

Yamazaki, K., Beauchamp, S.K., Matsuzaki, O., Kupniewski, D., Bard, J. \& Thomas, L. (1986) Influence of a genetic difference confined to mutation of $\mathrm{H}-2 \mathrm{~K}$ on the incidence of pregnancy block in mice. Proc. natn. Acad. Sci., U.S.A. 83, 740-741.

Received 24 September 1987 